\title{
SISTEMATIZACIÓN DEL CONTEXTO RELIGIOSO MAPUCHE A LA LUZ DEL PENSAMIENTO DE RUDOLF OTTO
}

Systematization of the mapuche religious context to the light of the thought of RudolfOtto

\author{
GUILLERMO TOBAR LOYOLA \\ Universidad San Sebastián-Puerto Montt (Chile) \\ guillermo.tobar@uss.cl; gtobarl@gmail.com
}

Resumen

El artículo busca observar el hecho religioso mapuche, a partir de la reflexión de Rudolf Otto respecto de lo numinoso y lo santo. Para ello se utiliza su metodología de análisis fenomenológico aplicada a los conceptos de mysterium, tremendum y fascinans o las dimensiones del temor, incorporadas en la cultura mapuche. Se concluye que el análisis de estos diversos momentos de la experiencia santo-numinoso en la vida religiosa del mapuche, permite constatar el dinamismo existente en la idea religiosa del mapuche, lo que a su vez representa adecuadamente la relación entre el hombre religioso y lo santo.

Palabras clave: Misterio; fascinación; temblor; fenomenología; mapuche.

Abstract

This article seeks to observe the Mapuche religious fact, starting from Rudolf Otto's reflection on the numinous and the holy. For this, it uses its methodology of phenomenological analysis applied to the concepts of mysterium, tremendum and fascinans or the dimensions of fear, incorporated in the Mapuche culture. It is concluded that the analysis of these different moments of the saint-numinous experience in the religious life of the mapuche, allows to verify the dynamism existing in the religious idea of the mapuche, which in turn represents adequately the relationship between religious man and the Holy.

Key words: Mystery; fascination; tremor; phenomenology; mapuche.

\section{INTRODUCCIÓN}

En 1917, cuando todavía daba lecciones en Bratislava, Otto publicó su obra Lo santo (Das Heilige), libro que lo hizo célebre por la profundidad y novedad con que desarrolla el aspecto religioso. El presente artículo busca observar el hecho religioso mapuche, a partir de la reflexión de Otto respecto de lo numinoso y a lo santo. El autor que describe el alma religiosa ha sido un pionero al buscar la comprensión del hombre religioso y de su experiencia sagrada, según Ries, "Otto mostró la experiencia de lo sagrado como experiencia humana de lo transcendente y lo inefable" (Ries, 1995, p. 13).

En consecuencia, se aplica un análisis de su método fenomenológico, destacando con ello los diversos momentos de la experiencia santo-numinosa en el hombre bajo un sentimiento de índole religioso. Es decir, se hallan elementos válidos para explicar y describir los diversos momentos de la experiencia interior del homo religiosus mapuche, 
como son el mysterium, tremendum y fascinans o las dimensiones del temor ${ }^{l}$ (Mondin, 2006, p. 108). A continuación se desarrollan estos términos desde la perspectiva del pensamiento de Otto y se aplican a la experiencia religiosa mapuche.

\section{DESARROLLO}

\section{II.1. LO NUMINOSO COMO MYSTERIUM}

El numen se caracteriza fundamentalmente como mysterium (o mirum o mirabile), como ese ser que es totalmente otro (Otto, 1985, p. 39-40). Lo numinoso está constituido por un elemento irracional (p. 10) mediante su categoría a priori. En cuanto irracional, se experimenta en el "puro sentimiento". Sin embargo, lo numinoso a pesar de ser irracional (Otto, 2014, p. 45) exige de alguna manera ser tocado o penetrado por lo racional, de este modo puede fijar sus propias características con ciertas señales que sean universalmente válidas; de lo contrario, estaríamos ante un elemento meramente ficticio, producto más bien de la imaginación que de la realidad. Otto afirma que dicha categoría a priori puede tener una estructura sólida y veraz que la convierta en una doctrina objetivamente válida y no, por el contrario, en una doctrina soñadora y fantástica basada en un elemento irracional (Otto, 2014, p. 155-160). En este mismo sentido, "Frente al cielo -señala Julien Ries-, el hombre parece haber tenido la impresión de una teofanía, plenitud cósmica y presencia al hombre" (1995, p. 31). Por su parte, el filósofo estadounidense Robert Davidson al tratar lo numinoso en Otto, señala que este sentimiento aparece especialmente claro en el nivel primitivo de la religión (Davidson, 1947, p. 58).

Frente al sentido ambivalente que puede presentar el término "primitivo" debemos señalar que el interés de Otto -al escribir su obra Lo santo- se enmarca en la óptica de conciliar los fundamentos de la religión dentro de los límites y posibilidades que ofrece el acceso racional a la cuestión de lo divino. Con ello el término primitivo en este contexto hace referencia al talante interior del homo religiosus y su sentido original de lo sagrado, cuyo análisis se da a partir de la ciencia, de lo racional y de lo irracional en la idea de Dios. Así pues, el concepto "primitivo" de la religión en Otto no se confunde ni se relaciona con el sentido evolucionista que se otorgó a este término por parte de algunos etnólogos e historiadores de la religión, sobre todo a partir de la segunda mitad siglo XIX, como sucedió

\footnotetext{
${ }^{1}$ Battista Mondin, en su intervención en la V Sesión Plenaria de la Pontificia Academia Sancti Thomae, que introduce el tema de lo santo en el siguiente sentido: «La percepción del sacro no es obra de la razón ni tampoco de la fantasía o de los sentidos. La sacralidad emana de una montaña (sacra), de un río sacro, de una persona sacra sacro, no se coge de los sentidos, tampoco del intelecto, sino de un particular sentimiento que no es aquel estético con el que se coge la belleza, ni tampoco aquel axiológico con el que se coge el valor de una acción o de una cosa, más bien del sentimiento religioso. "Es una resonancia psíquica, un sentimiento acompañado de una emoción de reverencia, si obsequio, de adoración, de sumisión, de fascinación y también de temor y temblor" (Mondin, 2005, p. 108, mi traducción).

308 | Alpha No49 (Diciembre 2019) PÁGS. 307-320. ISSN 07 16-4254
} 
-por ejemplo entre otros- con Augusto Comte, padre del positivismo, y sus tres etapas o estadios por los que evolucionó la religión: desde el teológico, pasando por el metafísico o abstracto y concluyendo con el estadio positivo o científico. Lejos de esta idea primitiva vinculada a la evolución, Otto considera en la experiencia religiosa del hombre la presencia de un "Algo" capaz de transformarlo y que él llama "el totalmente otro" (Der GanzAndere). Así, frente a este "Algo" la religiosidad primitiva para Otto se interpreta en razón de un sentimiento de creatura en el hombre, con el que se adentra en una experiencia vital de lo sagrado envuelta en el Mysterium de lo Tremendum y de lo Fascinans.

Al ser la religión mapuche principalmente cósmica y telúrica, la observación y vivencia de los fenómenos naturales crean un ambiente propicio para disponer religiosamente el ánimo de la gente de la tierra. Por otra parte, al ser la religión mapuche primitiva -en el sentido ottoniano del término- se evidencia de mejor modo en ella las características numinosas descritas por Otto. El temprano testimonio de los primeros cronistas acerca de las costumbres y la vida en territorio chileno lo deja en evidencia (De Bibar, 1966, p. 133). Esta constatación inicial marca el derrotero que tendrá esta práctica religiosa a partir de una disposición interior de apertura a lo divino en total correspondencia con la naturaleza. La disposición en el ánimo del mapuche se realiza de forma natural y espontánea, ya que el sentimiento religioso reposa en el ser humano en cuanto poseedor de una naturaleza racional tal como se evidencia en el mito de TrengTreng y Kai-Kai. En consecuencia, "el origen del pueblo mapuche echa sus raíces a partir de un relato mítico rico en seres zoomórficos que se encuentran en estrecho contacto con la naturaleza, en especial con los montes y sitúan el origen mapuche dentro de un gran y caótico evento diluviano" (Tobar, 2016, p. 66).

La fuerza del mal enfrentada a la potencia del bien, representada en el choque de las serpientes, despierta en el mapuche un sentimiento de pequeñez y de temor, que al mismo tiempo acentúa la grandeza y trascendencia de Ngenechén (dios mapuche) que lo sobrepasa (De Rosales, 1877, p. 155). La idea racional de lo absoluto desplegado en el evento ancestral, junto con todas las características de perfección, bondad o incluso de maldad que se entrecruzan en la narración del mito "no proceden ni se desarrollan de ninguna clase de percepción sensible" (Otto, 1985, p. 155).

El misterio, según Otto (p. 23), constituye el punto de partida en la experiencia que se hace de lo santo. De forma análoga, por medio del término mapuche feyentún ${ }^{2}$ (Curivil, 1995, p. 38) entendido como el conjunto de creencias mapuches que definen su religión, el indígena experimenta el ser supremo - manifestado fundamentalmente en Ngenechéncomo el dios de los mapuches, es decir, como creador y gobernador de los mismos. El

\footnotetext{
${ }^{2}$ El término feyentún "se puede traducir por creencias, pero se trata de creencias que solo tienen sentido en cuanto pueden ser vivenciadas mediante ritos ceremoniales. Por eso, quienes dicen por ejemplo taiñ feyentún, están haciendo referencia a un 'corpus de creencias' que en lengua winka constituiría la religión mapuche" (Curivil, 1995, p. 38).
} 
misterio del que habla Otto puede ser sentido de varias maneras: en el suave flujo del ánimo o en el sentimiento sosegado del alma(Otto, 1985, p. 23). Envuelto en este mismo misterio se halla el dios mapuche, misterio que, además, está en estrecha relación con el conjunto de creencias que sostiene y da vida a su religión (feyentún). Se piensa en el culto a los espíritus de los antepasados, en el culto de los muertos y de los ngen como espíritus que habitan en los diversos elementos de la naturaleza (p. 39). Todos ellos apuntan a identificar las distintas deidades presentes en el espectro religioso mapuche con un único ser supremo como es Ngenechén. De hecho, durante los rituales, con frecuencia se invoca a la divinidad por medio de diferentes nombres, que para el mapuche expresan diversos atributos de Ngenechén (Faron, 1997, p. 51).

En este sentido y más recientemente Bacigalupo, en el estudio dedicado al concepto de Ngenechén como dios mapuche busca distinguir, mediante una visión crítica de las fuentes y el testimonio de mapuches actuales, los elementos propiamente mapuches del concepto de Ngenechén y aquellos que se incorporaron por influencia del cristianismo (Bacigalupo, 1995-1996, p. 44) Parte de sus conclusiones señalan que en el concepto de ser supremo, asumido por los cronistas, misioneros y viajeros de la época, se mezclaron los siguientes términos: Ngünechen (hacedor del mundo y del hombre por voluntad propia) y Ngünenchen (el que confunde o convence al hombre con mentiras y embustes). Ambos términos se confundieron entre sí al grado de escribirlos de formas distintas, pero asumiendo que se trataba en todos los casos de un término equivalente. Lo mismo ocurrió con los términos de Ngenelchen (dejador o hacedor de la gente, dueño y creador del hombre) y Ngenechén (dominador del hombre). Nuevamente, ambos términos fueron confundidos entre sí y utilizados indistintamente (p. 47).

Como sea que se haya generado la conceptualización del ser supremo en Ngenechén, hemos de reconocer que este término expresa realmente al dios mapuche, o mejor dicho Dios mismo se hace presente mediante el misterio en la cultura y en el sentimiento del mapuche. Por esta razón no siempre se ve a Dios en un primer momento, porque la forma ordinaria en la que se presenta a los hombres es la del misterio, hecho silencio en la grandiosa manifestación de la naturaleza. Para el espíritu atento y sensible del mapuche, el semblante de Dios aparece como algo difícilmente explicable; tal vez esta misma experiencia le ha llevado a la identificación de diversas deidades, cada una con una característica de potestad propia.

Frente a esta realidad divina envuelta en el misterio, las palabras humanas parecen débiles e incapaces de comprenderlo. Es por ello que existe una enorme diversidad de términos divinos (Ngenechén, Chau Ngenechén, Füta Newen, Elmapun, Elchen, entre otros), cada uno con una significación propia que busca, de algún modo, comprender la naturaleza de la divinidad. Por su parte, la deidad mapuche, comprendida como ser 
supremo, que aparece con estas características, se convierte en un ser lejano ${ }^{3}$ e inalcanzable que, no obstante, se deja alcanzar por el mapuche por medio de múltiples manifestaciones de cercanía, sobre todo por su religiosidad, por sus ritos, sus invocaciones y rogativas. Ngenechén se presenta al mapuche como un Dios totalmente independiente, sin ninguna necesidad esencial procedente de sus creaturas. Por el contrario, el mapuche no puede dejar de depender de él; una muestra de ello es la rogativa en su honor durante el nguillatún.

\section{II.2. LO NUMINOSO COMO TREMENDUM}

Un aspecto fundamental de la percepción del tremendum es la consideración de la propia miseria, de estar en pecado y, por esta razón, del miedo a la cercanía del numen. En esta manifestación de lo numinoso, lo divino se experimenta como algo inaccesible y tremendo. La experiencia religiosa suscita, en el hombre, un estado psicológico análogo al temor, al miedo y al pavor. Con estas características se presenta lo santo, provocando en el ánimo un peculiar reflejo sentimental (Otto, 1985, p. 22-31). Ante esta realidad numinosa el mapuche trata de penetrar aquel misterio que aparece en su vida y en la naturaleza con tanta fuerza que no le deja indiferente. Frente a este ser, el mapuche queda completamente estupefacto (Dowling, 1971, p. 57), al punto de entrar, en ocasiones, en arrobamiento debido a la intensidad de la experiencia. Tal vez una muestra clara del sobrecogimiento lo manifiesta la machi cada vez que entra en contacto con la divinidad: "en el éxtasis me fui al cielo; allá me proveía el dios con excelentes dones" (De Moesbach, 1930, p. 340).

En efecto, la machi procura entrar en contacto con la divinidad para tener éxito en su labor tanto curandera como chamánica. Esta manifestación de la machi, aun cuando pudiese considerarse también una manifestación del fascinans, se estima dentro de la dimensión del tremendum, porque se trata de la aceptación de un oficio del que inicialmente se intenta huir por el temor que implica su ejercicio; la machi durante el proceso de "discernimiento" experimenta un hondo sentido de responsabilidad (¿obligación?) frente al hecho de haber sido elegida por Dios para esa función. La machi se resiste inicialmente porque es consciente de que no se trata de algo buscado o querido por ella, sino más bien intuye que se trata de algo "impuesto" por alguien superior de quien difícilmente se zafará. Es propiamente en este momento en el que aparece la radicalidad de aquella "llamada divina": la futura machi no tiene otra alternativa más que

\footnotetext{
${ }^{3} \mathrm{Al}$ verificar la idea de un dios lejano en la experiencia religiosa mapuche, se observa que se trata de una categoría fenomenológica no desarrollada en el pensamiento de Otto y distinta a la concepción absolutamente heterogénea de la divinidad que hace. Consultar las siguientes obras: Geo Widengren, Fenomenología de la religión (1976); Raffaele Pettazzoni, L'essere supremo nelle religioni primitive (1957); Raffaele Pettazzoni, El ser supremo: estructura fenomenológica y desarrollo histórico en: Mircea Eliade; Joseph Kitagawa, eds. Metodología de la historia de las religiones (1967).
}

AlPHa No 49 (Diciembre 2019) PÁGS. 307-320. ISSN 07 16-4254| 311 
aceptar. De aquí lo tremendo de su relación con la divinidad. El huir o rechazar semejante condición significa para la machi echarse encima varias desgracias que podrían incluso acabar con su vida. Los golpes de su tambor (cultrún) producen efectos de autohipnosis: "Entonces ella se extasiaba mucho -relata el lonco Pascual Coña-, profiriendo las palabras siguientes: "los buenos nobles del cielo me han elegido y visitado..." (De Moesbach, 1930, p. 332).

Esta condición sobrecogedora pasa por varias fases en la experiencia religiosa del mapuche, siendo su punto de partida la observación y su interacción con la naturaleza. El mapuche se estremece cuando la naturaleza habla y cuando igualmente calla. Nunca será indiferente frente a estos fenómenos naturales. Es el mapuche entero el que experimenta en su ser la inquietud del misterioso manto sagrado zurcido en la naturaleza. La mayor parte de las veces eriza la piel y sobrecoge su espíritu. Solo así se concibe en ocasiones que el mapuche no quiera "entender" lo que hay detrás de un rayo rasgando la oscuridad de la noche, sino más bien solo "sentirlo" para adorarlo impertérrito en el lado más íntimo de su ser. Tal vez por ello, el poeta mapuche Leonel Lienlaf escribió que: "Hay muchas cosas que el mapuche nunca ha tratado de explicarse... la cultura occidental está llena de porqués... no hay para qué preguntarse, es perder el tiempo. Lo que importa es cómo el hombre viva y cómo sienta la vida. La respuesta la podemos obtener viviendo. Las cosas van respondiéndose en la medida que evolucionamos"(Sierra, 1992, p. 67).

También se observa el concepto religioso más antiguo que consideraba a pillán como la deidad más poderosa y tremenda, al mismo tiempo era asociada a los increíbles eventos de poder y temor que la actividad volcánica imponía con cierta frecuencia en la tierra mapuche. El padre Febres señala en 1764 lo siguiente: "Pillañ, pillan llaman al Diablo, o a una causa superior, que dicen hace los truenos, rayos, relámpagos, y reventazones de volcanes, y a estos mismos efectos también llaman Pillañn" (Febres, 1764, p. 593). También Havestadt en 1777 da su descripción acerca de la naturaleza de pillán en términos muy semejantes y en latín: Pillan, causa prima, cui varios effectus naturae Tornitrua, fulgura, fulmina, aliaque ejusmodi attribuunt (p. 745).

Considerando la actividad volcánica en estrecha relación con el poder atribuido a pillán, Lenz nos ofrece una reflexión que se acerca bastante a la idea del numen como tremendum: "No es extraño que los indios de Chile hayan considerado las erupciones volcánicas y todos los fenómenos luminosos del firmamento, que en Chile se observan principalmente concentrados en las altas cumbres de la cordillera; como la manifestación más imponente de una fuerza superior, es por esto probable que también hayan relacionado el temblor, tan frecuentemente compañero de erupciones volcánicas, con el concepto de Pillan" (Lenz, 1912, pp. 7-8). Para este mapuche "sorprendido" por la prepotencia de los fenómenos de la naturaleza, es necesario conectarse vivencialmente con la divinidad. 
Asimismo, se puede considerar cómo el mapuche se empeña en representar lo divino por medio de extraños objetos y formas igualmente sorprendentes. En la manifestación de su religiosidad existen representaciones de la divinidad en animales, en plantas, en seres fantásticos y fenómenos de la naturaleza. Se trata de una forma peculiar del idioma mapuche de involucrar diversas personas para expresar distintas cualidades 0 formas de ser de Dios (Alonqueo, 1979, p. 223).

La exteriorización del sentimiento interior mapuche ha sido el elemento que más ha ayudado a definir su experiencia religiosa. Otto se empeña en señalar y definir esta tonalidad sentimental, con ciertas comparaciones, analogías y contraposiciones de otros sentimientos afines y de expresión simbólica (Otto, 1985, p. 22).

En esta propiedad de lo numinoso que Otto presenta bajo términos de "majestad tremenda" sobresalen dos aspectos ontológicos que se relacionan entre sí. Por una parte, el mapuche experimenta su propia inconsistencia, su finitud, su pequeñez; se hace consciente de su ser como creatura, de su dependencia de un ser supremo. Por otra parte, experimenta a este ser como "totalmente diferente" (p. 40) como un ser en grado sumo, que tiene el poder de manera sobreabundante. Los títulos divinos que otorga el mapuche a este ser expresan la naturaleza de esta realidad: Fütrachaw (El gran Padre); Fütranewen (El gran Espíritu); Creador del hombre (Ngenechén); Creador o Patrón de la tierra (Ngenmapun); Creador de la tierra (Elmapun).

En una de las rogativas del camaruco (denominación del nguillatún en algunas regiones patagónicas) realizadas por Ceferino Caitrú, maestro de ceremonias de la rogativa, se encuentra la siguiente rogativa que refleja la pequeñez y dependencia del mapuche frente al ser supremo: "Ya vengo a hincarme y rogar. Hasta los blancos llegan a este lugar, al camaruco. Si satisfago al Viejo Padre, a Nguenechén, voy a pasar un buen año, voy a estar bien. Porque soy huérfano. No estoy para mandarme solo. Porque soy pobre. Poco sé hablar la lengua. No me mando solo. El que me creó me dio buena cabeza. Me dio buena lengua"(Fernández, 1995, p. 124). El mapuche, reconoce su realidad frente a Ngenechén, de ahí que experimente una radical finitud, surgen en él una cierta desestima que rápidamente se convierte en exigencia, es decir, en desilusión o aniquilamiento del yo: "No estoy para mandarme solo", expresa.

De esta manera se explica el pavor y el estremecimiento que experimenta el mapuche ante esta superioridad que lo sobrepasa. Un buen ejemplo de ello nos lo presenta el estudio hecho por Mora Penroz del significado de algunas palabras en mapudungún (Mora, 2001, pp. 28-29), puntualmente respecto de la partícula gü, güy que forman parte del prefijo de gülmen o üllmen, que se trata del título más prestigioso al que un mapuche puede aspirar. En la actualidad también se asocia el término con riqueza (Guevara, 1908, p. 24). La raíz gü significa "temor" y "rabia"; sin embargo, esta raíz - en opinión de Mora Penroz- proviene a su vez de una raíz más arcaica iui o üy que posee un triple significado: nombre, miedo y encender (Mora, 2001, p. 28). Para Mora Penroz, el concepto que está 
detrás de la semántica üi se puede expresar de la siguiente manera: "la idea de que dar nombre a alguien o algo es también, encenderlo (...). Además está revelando de paso que el nombre de una persona refleja también su 'miedo' personal (el temblor de los dientes) a no existir"'(p. 29). Sin embargo, es posible señalar que en la gramática de Félix de Agusta, el misionero capuchino no asimila en la traducción al mapudungún el concepto: nombre con encender. Lo interesante de descubrir este temor en la raíz semántica del término üllmen es que este temor nace de la contraposición al concepto divino Fütrachaw, el Gran Padre o Cuaternario Divino, el que "no tiene nombre porque es la única Realidad que no tiene miedo a no existir; lo demás, para superar ese miedo a la nada, necesitamos un $\ddot{u} y$, un nombre que nos haga 'arder en la existencia"' (p. 29). No se puede negar que el temor aparece como un elemento fundamental e importante en la vida de la religión mapuche que, por otra parte, adquiere otras dimensiones cuando se ve envuelto en la experiencia religiosa. El mapuche ante este temor que experimenta frente al misterio "se siente expuesto a un poder frente al cual no puede resistir, al cual no se le puede establecer ni regla ni límites y que puede disponer de él según su beneplácito, la mayor de las veces cruel y arbitrario" (Boublik, 1973, p. 83).

\section{II.3. LO NUMINOSO COMO FASCINANS}

Ocurre un fenómeno que a primera vista se podría considerar una contradicción existencial en la vida del mapuche que se enfrenta a la experiencia religiosa. La explicación a este fenómeno ambivalente tiene su fundamento cuando en la experiencia de lo numinoso se da una especie de "dualidad". Por una parte, se le ha descrito por medio del aspecto de lo tremendo, causando en el mapuche un miedo intenso y un deseo casi natural de huir. Por otra parte, esta misma experiencia de lo numinoso se presenta como algo que simultáneamente atrae, capta, embarga y fascina al mismo mapuche que antes deseaba huir. Incluso se produce un anhelo de dejarse poseer enteramente por dicha experiencia. De esta forma, la creatura no solo se siente intensamente atraída por lo numinoso, sino que además busca de alguna manera la posesión de este elemento fascinans. Este elemento irracional de lo fascinante se compone de ciertos conceptos racionales que Otto enumera de la siguiente manera: el amor, la misericordia, la compasión y la piedad; todos ellos son para él ingredientes naturales de la vida espiritual corriente (Otto, 1985, p. 52). Bajo esta óptica, se entiende la importancia de este elemento "maravilloso" en la experiencia religiosa: "seremos felices en esta tierra por tu voluntad" proclamó recién el ngenpin. En efecto, sobresale el valor de este elemento en cuanto mantiene equilibrada la presencia de lo santo en la creatura, pues de lo contrario el mapuche se vería de tal forma aterrorizado por la dimensión de lo tremendo que su experiencia religiosa del numen, en lugar de ser una experiencia de lo santo, sería una 
amarga y atormentada experiencia que, aun reconociendo lo santo, le haría profundamente desgraciado.

La opinión que los mapuches han transmitido al padre Félix de Augusta respecto de la divinidad refleja este sentido de lo fascinans: "Su casa es de puro oro, tal vez es el sol. Es bondadoso y accesible a las súplicas de los mortales, sus súbditos. Es Chau, Nenechen, Nenemapun Padre, Dominador de los hombres y de la tierra" (De Augusta, 1910, p. 227). En estas circunstancias, en las cuales el alma se encuentra totalmente presa por este sentimiento, ella quisiera expresarse máximamente, pero se ve limitada y solo logra expresar este sentimiento de forma negativa para de alguna forma así dar realce y vigor a la experiencia fascinante que ha tenido. Para Otto, como se aprecia en el siguiente texto, muchas veces este lenguaje "en negativo" es capaz de producir en el alma un verdadero embelesamiento: "Es muy instructivo para el caso que en estas palabras, por las cuales el sentimiento quisiera expresar su máxima tensión, 'el alma desiste de toda imagen' y solamente se expresa en lo negativo. Y es notable que al escucharlas o leerlas no percibimos en absoluto su carácter negativo. Por el contrario, podemos embelesarnos y hasta emborracharnos con series enteras de tales negaciones" (De Augusta, 1910, p. 55).

Por lo mismo, Otto señala que "existen himnos capaces de producir la impresión más profunda, en los que casi no hay ningún contenido positivo" (p. 55). En este sentido, podemos rescatar oraciones realizadas durante la investidura de una machi, que producen impresiones profundas y que, sin embargo, están expresadas de forma negativa. Un ejemplo del padre Félix de Augusta ${ }^{4}$ se recoge en el testimonio del lonco Pascual Coña: "Hoy, pues, seré machi perfecta, gracias a ti, dominador de los hombres, dios anciano y diosa anciana. No me pongas en apuros; yo no me hice machi por propia inclinación y voluntad; muéstrateme favorable para siempre para que sea machi poderosa (...)". (De Moesbach, 1930, p. 337). "Yo me enfermé porque seré machi; el dios del cielo me ha dicho: Yo te crearé machi y te proporcionaré eficaces oraciones. Realmente no estoy enferma; es el espíritu de machi que me atormenta; por eso he de asumir la profesión ahora" (p. 340). En estas líneas se muestra cómo la expresión que se evidencia por medio de conceptos es capaz de ser entendida en toda profundidad por el sentimiento. Por ello, Otto dice que el simple amor, la mera confianza, por mucha felicidad que engendren, no explican este poder de rapto y enajenación que obra en nuestros cánticos de gracia (Otto, 1985, p. 56). Agrega que a esto le falta un "algo más" y que en definitiva es lo "fascinante" (Otto, 1985, p. 57). Sin duda, esta sensación es tan real como su presencia en el sentimiento del mapuche. En efecto, cuántas veces este es consciente de no haber entendido todo; sin embargo, hay algo en su interior que bulle y que a la vez le insinúa con insistencia ser ese "algo más"(p. 57).

La realidad se evidencia en el hecho de que existe un "algo más", lo que a su vez exige del mapuche una constante disposición positiva de búsqueda a la respuesta de esa

${ }^{4}$ Misionero capuchino de la provincia de Baviera (1860-1935).

AlPHa No 49 (Diciembre 2019) PÁGS. 307-320. ISSN 07 16-4254| 315 
experiencia. La respuesta se buscará en las rogativas, en el sacrificio, en la relación con los espíritus de la naturaleza y en la observancia del admapu. El elemento irracional fascinante puede, además, presentarse en el alma con mayor o menor fuerza, con "mayor o menor preponderancia". De aquí surge la posibilidad de llevar al alma a un estado místico de profunda quietud del espíritu y al arrobo, en los cuales casi llena por sí solo el volumen del alma (p. 59). En el caso del mapuche, esta realidad de "alma mística" se puede constatar en la facilidad y espontaneidad de su oración, en particular la de la machi durante las rogativas. La peculiaridad de esta oración mapuche consiste principalmente en tratarse de oraciones ni fijas ni uniformes, lo que se explica por ser plegarias sin una elaboración previa, sino más bien por ser espontáneas e inspiradas por la divinidad (Alonqueo, 1979, p. 61). La oración del mapuche surge en el momento mismo en el que se requiere de ella; brota esta súplica del sentir íntimo del ejecutante de la rogativa a causa de una provocación religiosa, que inspira y guía sus palabras y ademanes. Esta misma

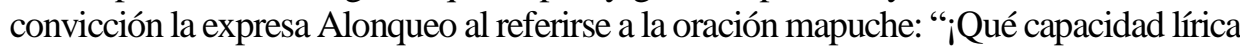
no tendrán estas orantes mapuches, para poder orar casi sin parar durante días enteros, sin repetirse y llevar a su gente a una oración con su Dios!" (p. 61). Asimismo, después de una larga y extenuante rogativa en la que se mezcla el canto, el baile y la oración, la machi oficiante de la impetración realiza una breve pausa para tomar fuerzas y continuar. Alonqueo recoge este hecho en su libro en la persona de la machi Lucinda Lincoñir, de quien dice lo siguiente: "Sopla con suspiros profundos para disipar el cansancio después de la larga recitación entonada de sus canciones; toma agua para refrescarse y hace asperges como expresión de gracias a su Ngënechén"(p. 82).

Haciendo alusión a este punto, Otto escribe en uno de los capítulos de Lo santo lo siguiente: 'Hemos de aludir aquí a ese 'no poder' decir nada de lo que se ha 'vivido' propiamente, a la dichosa conmoción de la que no nos podemos soltar, a la exaltación y aun a ciertas formas anormales y extravagantes en que pueden traducirse estas emociones"(p. 60). Así pues, siendo esta no una experiencia sensible sino espiritual, el intelecto no admite nuevos conceptos que vengan de los sentidos, sino que se infunde en el alma un inexplicable sentido de Dios. También, la sensibilidad hacia la naturaleza va más allá de la mera admiración y de la simple contemplación ${ }^{5}$ (De Oña, 1917, p. 180).

De esta manera, aparece la transformación progresiva de lo fascinante en algo excesivo (Otto, 1985, p. 60), es decir, en algo que llena completamente el alma de esta experiencia de lo divino hasta llegar a esta "beatitud religiosa", como la llama Otto.

\footnotetext{
${ }^{5}$ El poeta Pedro de Oña en el canto V de su poéma épico, relata el caminar de Caupolicán junto a su Fresia presurosa, señalando lo siguiente: "Y marchan hasta cuando el sol dorado, huyendo de la noche tenebrosa, que a más andar siguiéndole venía, al mar, como a sagrado, se acogía” (De Oña, 1917, p. 180).

316 | AlpHA No49 (DiCIEMBRE 2019) PÁGS. 307-320. ISSN 07 16-4254
} 


\section{DISCUSIÓN}

Para el mapuche es una exigencia natural expresar devoción y reverencia al dios Ngenechén en cuanto ser sagrado. Esta reverencia a la divinidad constituye, en palabras de Otto, "un momento de fuerte conmoción lo más exclusivamente religioso que sea posible", es decir, se hace presente en él un sentimiento propiamente religioso cuando mira y reverencia la unidad sagrada del universo.

Así pues, el análisis de estos diversos momentos de la experiencia santo-numinoso en la vida religiosa del mapuche, permite constatar el dinamismo existente en la idea religiosa del mapuche, lo que a su vez representa adecuadamente la relación entre el hombre religioso y lo Santo.

Se devela la relación del mapuche con la creencia de un ser supremo, por medio de lo que se puede denominar una conmoción religiosa. Esta conmoción o hecho religioso es suscitado por medio de un estado de ánimo particular en el mapuche, cuya realidad está sumida en un misterio de naturaleza ambivalente: el mapuche responde ante la revelación de este misterio desde lo tremendo y a la vez desde lo fascinante. Ambas categorías dan sentido a toda la realidad humana, incluso al mundo de lo profano el que es tocado e iluminado por el Misterio y la trascendencia.

La fenomenología de Otto permite identificar y luego describir los diversos momentos en los cuales se expresa esta experiencia religiosa. Con ello se responde activamente a la vivencia de la religiosidad mapuche, sintetizada en una actitud personal en búsqueda de un encuentro con lo sagrado, frente a ello lo religioso se manifiesta en todos los ámbitos de la vida, en su visión del cosmos, en el arte, en la música, en el juego y en la salud entre otros.

El primer paso de acercamiento a esta experiencia religiosa se realizó mediante el término mysterium, cuyo propósito fue identificar lo sagrado con la actitud mapuche de superponer toda actividad humana a la acción del ser supremo. Cuando actúa en ellos la presencia numinosa de este ser; bailes, cantos, comida y hasta la misma guerra alcanzan un sentido sublime y de profunda conexión con lo divino. El cielo, la tierra, las plantas, los animales, e incluso el oculto, pero activo mundo de los espíritus de la naturaleza (ngen), conforman esta rica y dinámica experiencia sagrada, comprendiendo que la vida y la muerte penden de un hilo si su gobierno y acción no vienen de lo alto.

Pero la experiencia numinosa de lo santo se muestra ambivalente, al parecer se trata de dos caras de una misma moneda. En la primera de ellas la extraordinaria potencia que inspira su naturaleza divina toma un ropaje de ira y furor (tremendum), frente a ello el mapuche experimenta un profundo sentimiento de temor y angustia. Aquel ser supremo se presenta ahora bajo una dimensión que lo subyuga interiormente, se siente pequeño, indefenso, necesitado del auxilio divino sin el cual podría perderse para siempre. Los fenómenos de la naturaleza como el violento tronar de los volcanes, la lava ardiendo cerro abajo debido a su erupción o el impetuoso movimiento de un terremoto 
seguido de un devastador tsunami son una clara manifestación de poder y de temor impuesta por la deidad. La percepción de lo tremendum en el interior del mapuche infunde un profundo sentimiento de dependencia y anonadamiento, estupefacto ante esta realidad explora su miseria personal invocando a sus ancestros para que le enseñen el camino de la observancia del ad mapu (leyes y preceptos), para poder así ser gratos a los ojos de Ngenechén.

La otra cara de la moneda parece evidenciar una cierta dualidad ante la presencia de lo numinoso. Si bien es cierto este ser supremo es una deidad poderosa y fuerte que impone temor, es al mismo tiempo un ser cuya potestad se expresa con suavidad (fascinans). Es la cara amable de la deidad aquella que le basta una pequeña mueca para llenar de dicha la existencia del mapuche y atraerlo irresistiblemente hacia sí. Se trata de la característica fascinans desplegada por Ngenechén que logra embargar su ánimo y dirigir su actuar. La naturaleza y su relación con la tierra se presentan de una manera armónica, conforme a una relación tanto agradable como seductora entre el mapuche y la divinidad. Con lo que se entiende el conocimiento acabado que poseen de aves y animales que habitan sus bosques, de plantas y árboles que incorporan en su medicina y en general de la geografía que los circunda. Conocen con precisión la tierra porque es parte de su propio cosmos, la cuidan porque en ella actúa y se expresa lo numinoso. En su relación con ella no solo se deja ver su comprensión territorial de la misma, también sobresale la convicción de estar ante un mundo que lo abarca todo: lo que está arriba, lo que está abajo y lo que pisan sus pies. Este es el mundo en el que se representa existencialmente la reciprocidad entre el pueblo mapuche y la tierra bajo el amparo sagrado de la acción de Ngenechén.

En suma, se constata que la experiencia religiosa que hace el mapuche de lo santo se presenta como un misterio que no tiene que ver con algo inaccesible ni oculto, sino como algo plenamente experimentable y existente como una realidad que, aunque lo supera y trasciende es capaz igualmente de "tocarlo" y "sentirlo". La sencilla y honesta disposición del espíritu mapuche hacia el conocimiento de lo numinoso, permite que el Misterio sagrado de lo fascinans y de lo tremendum se le revele en concomitancia con la experiencia que hace del mismo.

Los datos de análisis vertidos en el presente artículo como también los distintos conceptos utilizados en mapudungún no fueron revisados con hablantes nativos para una posible confrontación de los mismos, en su lugar se escogió la reproducción y autoridad de fuentes escritas, asumiendo con ello el riesgo de posibles interpretaciones personales de ciertos conceptos en mapudungún. 


\section{OBRAS CITADAS}

Alonqueo, Martín (1979). Instituciones religiosas del pueblo mapuche. Santiago: Pontificia Universidad Católica de Chile.

Bacigalupo, Ana Mariela (1995-1996). "Ngünechen, el concepto de dios mapuche", en Instituto de Historia, PUC No 29, 43-68.

Boublik, Vladimìr (1973). Teologia della Religione. Roma: Studium.

Curivil, Ramón (1995). Religión mapuche y cristianismo, en ¿Modernización o sabiduría en tierra mapuche? Santiago: San Pablo.

Davidson, Robert (1947). Rudolf Otto's interpretation of religion. Princeton: Pinceton University Press.

De Augusta, Félix (1910). Lecturas araucanas (Narraciones, costumbres, cuentos, canciones, etc.). Valdivia: Imprenta de la Prefectura Apostólica.

De Bibar, Gerónimo (1966). Crónica y relación copiosa y verdadera de los Reino de Chile (1558). Santiago: Fondo Histórico y Bibliográfico José Toribio Medina.

De Moesbach, Ernesto Wilhelm (1930). "Vida y costumbres de los indígenas araucanos en la segunda mitad del siglo XIX". Revista Chilena de Historia y Geografía, Imprenta Cervantes.

De Oña, Pedro (1917). Arauco domado. Edición crítica de la Academia Chilena correspondiente de la Real Academia Española. Santiago: Imprenta Universitaria.

De Rosales, Diego (1899). Historia General del Reino de Chile, Flandes Indiano. Valparaíso: Imprenta el Mercurio.

Dowling, Jorge (1971). Religión, chamanismo y mitología mapuche. Santiago: Universitaria. Faron, Louis (1997). Antüpaiñamko: moral y ritual mapuche. Santiago: Mundo.

Febres, Andrés (1764). Arte de la lengua general del Reino de Chile. Lima: Encarnación. Fernández, César (ed.) (1995). Cuentan los mapuches. Buenos Aires: Nuevo Siglo.

Guevara, Tomás (1908). Psicología del pueblo araucano. Santiago: Imprenta Cervantes. Havestadt, Bernhard (1777). Chilidúgú, sive Res Chilenses, Vol. II. Münster: Typis Teubneri.

Lenz, Rodolfo (1912). Tradición e ideas de los araucanos acerca de los terremotos. Anales de la Universidad de Chile, Tomo CXXX. Santiago: Imprenta Cervantes.

Mircea, Eliade; Kitagawa, Joseph, eds. (1967). Metodología de la historia de las religiones. Buenos Aires: Paidós.

Mondin, Battista (2006). "La trascendentalità del Sacro e la sua fondazione metafisisca, Pontificia Academia Sancti Thomae Aquinatis, Doctor Communis", in Atti della V Sessione Plenaria 24-26 Giugno 2005, Ciudad del Vaticano.

Mora, Ziley (2001). Filosofia mapuche, Palabras Arcaicas para Despertar el Ser. Concepción: Kushe. 
Otto, Rudolf (2014). Mística de Oriente y Occidente, traducción y notas de Manuel Abella. Madrid: Trotta.

— (1985). Lo santo. Lo racional y lo irracional en la idea de Dios. Madrid: Alianza.

Pettazzoni, Raffaele (1957). L'essere supremo nelle religioni primitive. Torino: Einaudi.

Ries, Julien (1995). "El hombre religioso y lo sagrado a la luz del nuevo espíritu antropológico" en J. Ries, (ed.) Tratado de antropología de lo sagrado: los orígenes del homo religiosus. Madrid: Trotta.

Sierra, Malú (1992). Un pueblo sin Estado: mapuche, gente de la tierra. Santiago: Catalonia. Tobar Loyola, Guillermo (2016). Mito camino de una experiencia. Santiago: UFT.

Widengren, Geo (1976). Fenomenología de la religión. Madrid: Cristiandad. 